\section{Encyclopedia of Materials: Science and Technology}

K.H. Jürgen Buschow, Robert W. Cahn, Merton C. Flemings, Bernhard Ilschner,

Edward J. Kramer, and Subhash Mahajan, Editors

(Elsevier, Oxford, UK, 2001)

10,387 pages; $\$ 6,875.00$

ISBN 0-08-043152-6

\section{Genesis}

The first encyclopedia on materials ever to be produced was the eight-volume compilation edited by Michael Bever in 1986. This was succeeded in 1994 by the more narrowly focused work, Encyclopedia of Advanced Materials, edited by D. Bloor, R.J. Brook, M.C. Flemings, S. Mahajan, and R.W. Cahn. The present work (EMSAT) consists of 11 volumes, totaling more than 10,000 pages, and was organized by the six co-editors in chief, assisted by 62 subject editors. The resulting volumes, covering virtually every aspect of the subject, comprise some 1795 articles produced by over 2000 contributing authors.

\section{Overall Assessment}

The current review was composed by a group of present or former materials scientists from the General Electric Research and Development Center (now GE Global Research). Collectively, their expertise is very broad, encompassing thermodynamics and phase diagrams, metal-hydrogen systems, intermetallics, biomaterials, polymers, dendritic growth, dislocations, copper alloys, steels, radiation damage, glass, stress corrosion, carbon, crystal growth, cements, machining, tool materials, and high-temperature materials, among other topics. All agree that EMSAT is extraordinarily comprehensive, authoritative, current, well-illustrated, and intriguing to browse as well as helpful in seeking particular information. Coverage of any subject includes not only traditional areas but also emerging areas in that field. The reviewers found the treatment of the following areas particularly well done: polymer science and engineering, amorphous materials, metal-hydrogen systems, biomaterials, thermodynamics, phase diagrams, diffusion, superalloys, and point defects.

\section{Scope and Organization}

In addressing the broad subject of materials science and technology, the editors have considered four main categories of information: materials; their properties; techniques for their synthesis, for control of their structure at all levels, and for processing them into useful forms; and their diverse applications. Properties account for the largest category, with the others somewhat smaller and approxi- mately equal in volume. The classes of materials covered comprise biomaterials, carbon, ceramics, composites, electronic and optoelectronic materials, inorganics, magnetic materials, metals and alloys, polymers and plastics, and thin films of various types. The 50-page Thematic Guide presented in Vol. 11 breaks down each of the four main categories of topics into subcategories, sub-subcategories, and finally to article titles. Within the body of the EMSAT itself, the articles are arranged in alphabetical order by title, where the editors have sometimes altered the original title conceived by the author so as to bring related articles into close proximity. This was clearly a laudable objective, but sometimes fell short in execution. For example, "Casting of Intermetallics" appears with casting entries, not with the 15 or so other intermetallic articles; an article on "Poly-Crystalline-Silicon CMOS Devices" is buried, sandwiched between "Polycarbonates" and "Polydienes"; and an article on the uses of wood for musical instruments is not with the 40-odd other articles on types, properties, and applications of wood, but in the " $\mathrm{m}$ 's" for "Musical Instruments: Materials." Taking as another example an important broad topic, "Crystal Growth," one finds only four articles whose titles begin with those words and another six beginning "Growth...." It is here that the Thematic Guide of Vol. 11 exhibits its power and convenience, for looking under "Techniques and Processing" and in that group under the subgroup "Surfaces, Microand Nano-Scale Processing," and finally under the sub-subgroup "Crystal Growth," one finds listed titles of some 56 articles! A nice feature would have been to include in each volume a brief subject index to the topics covered in that volume, thus removing the irritation of repeatedly pulling out another volume, frequently yielding only a tiny bit of information.

\section{Articles}

Individual articles range in length from two to 18 pages, with an average length of 5-6 pages. Most articles incorporate illustrations, typically four or five (both black and white and color) as well as occasional tables. Some topics, although covered by five to 10 or more individual articles, seem to lack an introductory article indicating the relevance of the subject, including goals, barriers to full understanding, and unresolved issues. Instead, the authors of individual articles in a related group often focus only on particular aspects with which they are familiar and engaged and that do not relate to the general subject. Thus the reader often "can't see the forest for the trees." Readers are also cautioned that the depth and extent of treatment of particular subjects is variable across the EMSAT so that it should not be used as a sole source, but resort should be made as well to the books and articles noted in the bibliographies and to other sources.

On the other hand, the coverage of many topics is extraordinary! Take electronic packaging, for example, covered by 15 individual articles. In addition to general articles on this topic treating materials selection, design fundamentals, quality, and reliability, other highly specialized articles describe particular kinds of materials used in this application and pertinent processing techniques. It is difficult to imagine any other single source that could provide this level of detail.

Despite the extraordinary comprehensiveness of coverage, EMSAT still has some surprising omissions. For example, nothing is said of the history of the materials field (the one historical article that is included is difficult to find because it is not under " $h$ " in either the subject index or in the alphabetized sequence of article titles); no article treats resistance welding, an important industrial process; nothing is included on hexagonal boron nitride; little appears on cements other than bone cement and Portland cement; and only the briefest mention is made of the toxicity of beryllium (and that, not under "beryllium," but rather under "CVD Monofilaments"!). The writing in general is very good, erudite but clear. The authors' names are given at the end of each article, but the reader has to go to Vol. 11 to find their affiliations.

\section{Cross-Referencing and Bibliographies}

Cross-referencing to other related EMSAT articles is usually provided, either within the article itself or collected near the bibliography at the end of the article. In actuality, however, the cross-referencing feature is inadequate. Suppose the reader's interest is jet engine materials, for example. The article with that title has no cross-references! Yet, examination of the Thematic Guide in Vol. 11 under "Superalloys" leads to another article, "CreepResistant Superalloys," and under "NonFerrous Metals and Alloys," to two more: "Nickel-Based Superalloys: An Overview" and "Nickel-Based Superalloys: Alloying." Looking further under "Mechanical Properties, Fatigue" identifies still another, "Fatigue of Superalloys" (not included in the subject index). These four in turn point to 11 other articles. Yet none of these refer to other equally relevant articles which can be found in the index: two on metal-matrix 
composites, 14 on intermetallics, and one on surface coatings for high-temperature alloys. Similarly, there is an article, "Thermodynamics: Corrosion," which extensively discusses Pourbaix diagrams and another on "Metal Production: Ellingham Diagrams," but both fail to cross-reference the articles on those diagram types elsewhere in the encyclopedia. This serious shortcoming in cross-referencing, the fault of the editors, requires users to consult the general index as well as the Thematic Guide and alphabetical title list in order to find all that is relevant to the subject of their inquiry.

The bibliographies at the end of each article are not lists of citations but rather are recommendations on key papers, overview articles, and books that will enable readers to deepen their understanding of the topic concerned. Ideally, these should comprise not only the latest and best reviews of the topic but also a few relating to the beginnings of the subject. In this respect, the time range of suggestions offered by individual authors varies widely. For the majority of articles, the latest citations are for 1999-2000; some give no citations prior to 1990 , some none since 1988; yet others include references to the 1800s! Again, this points to a lack of oversight and control on the part of the editors. Although the bibliographies were intended as guides for further reading, not as citation lists, it is still surprising that breakthrough investigations and classic papers are usually not even mentioned.

\section{Electronic Version}

The editors and publisher agreed to place a complete electronic version of the EMSAT on the Internet simultaneously with the issuance of the printed set of volumes. It was intended that the electronic version would have more color images than are possible in print form and would also include multimedia features. The plan was to add regularly to the electronic version articles on new topics as well as to update original articles, especially their bibliographies. To date, 129 new articles have been added and five updated. Even though for each of these the year is indicated in which it went on-line, there is no easy way to select from the whole electronic encyclopedia those articles that supplement or update articles in the print edition. So far, the updating consists only of additions to the reference lists, not alterations or additions to the text of the articles.

\section{Index Volume}

The eleventh and final volume in the set comprises several indexes: the alphabetical list of titles; a 50-page thematic guide arranging article titles in a three-level classification system (e.g., materials, biomaterials, ceramics, four individual articles); an alphabetical list of subject editors and their areas of responsibility; an alphabetical list of contributors; a 322-page detailed subject index; and a 20-page list of acronyms and their definitions. (Unfortunately, not all acronyms used by the authors appear here.) The contributor list, showing the names and affiliations of the contributors, together with the title, volume, and page reference of their contribution(s), deserves special comment. Collectively, the contributors constitute an international group of outstanding materials scientists and engineers. The United States, United Kingdom, and Germany are most strongly represented, but more than 20 other countries appear as well; only Russia and India seem underrepresented. Most contributors authored but a single article, but a few indefatigable individuals are associated with as many as six. Inexplicably, an estimated 400 contributors to articles in the printed EMSAT are not included in the list of contributors! In 10 cases, the same individual is listed twice. The electronic version of the encyclopedia has corrected these problems.

\section{Summary}

The Encyclopedia of Materials: Science and Technology has no peer. Access to it is indispensable to anyone studying or working in the materials field. It is to be hoped that a new edition will appear within 10 years which would not only provide whatever updating might then be required, but also fill in the minor gaps noted and deal with the suggested modifications, especially as regards cross-referencing.

Review Team: J.H. Westbrook reviewed the Encyclopedia of Materials: Science and Technology series with assistance from R.C. DeVries, R.L. Fleischer, W.B. Hillig, R.P. Kambour, P.R.L. Malenfant, and J.C. Zhao, all who are currently or formerly of the General Electric Research and Development Center (now GE Global Research). 